\title{
Applicability of three complementary relationship models for estimating actual evapotranspiration in urban area
}

\author{
Takeshi Nakamichi ${ }^{1}$, Toshitsugu Moroizumi ${ }^{2 *}$ \\ ${ }^{1}$ Shimonoseki - city, 1-1 Nabe-cho, Shimonoseki city, Yamaguchi 750-8521, Japan. \\ ${ }^{2}$ Graduate School of Environmental and Life Science, Okayama University 1-1, Tsushima-Naka, 3-chome, Kita-ku, Okayama 700-8530, \\ Japan. \\ ${ }^{*}$ Corresponding author. Tel.: +81-86-251-8877. Fax:+81-86-251-8877. E-mail: morot@okayama-u.ac.jp
}

\begin{abstract}
The characteristics of evapotranspiration estimated by the complementary relationship actual evapotranspiration (CRAE), the advection-aridity (AA), and the modified advection-aridity (MAA) models were investigated in six pairs of rural and urban areas of Japan in order to evaluate the applicability of the three models the urban area. The main results are as follows: 1) The MAA model could apply to estimating the actual evapotranspiration in the urban area. 2) The actual evapotranspirations estimated by the three models were much less in the urban area than in the rural. 3) The difference among the estimated values of evapotranspiration in the urban areas was significant, depending on each model, while the difference among the values in the rural areas was relatively small. 4) All three models underestimated the actual evapotranspiration in the urban areas from humid surfaces where water and green spaces exist. 5) Each model could take the effect of urbanization into account.
\end{abstract}

Keywords: CARE model; AA model; MAA model; Potential evapotranspiration; Urban; Rural.

\section{INTRODUCTION}

Evapotranspiration from the land surface is the important factor for both heat balance and water balance. Reliable methods for evaluating regional evapotranspiration are needed in many fields of study, such as hydrology, meteorology, irrigation planning, and water availability, and so on. However, evapotranspiration is a really complicated phenomenon which varies according to surface water conditions, plant physiology, and meteorological conditions. This, therefore, makes it difficult to estimate the actual evapotranspiration from the land surface.

Several models have been proposed to estimate the actual evapotranspiration. One of them is the Penman-Monteith model, which was firstly introduced by Monteith (1965). This model has been successfully used to estimate evapotranspiration from different land uses. However, this approach requires such parameters as canopy resistance and aerodynamic resistance which depends very much on the wind speed, the atmosphere stability conditions and the height at which the weather data are measured. Without prior field surveys, therefore, it is difficult to apply this model to areas where the above parameters have not been obtained.

Another approach for estimating evapotranspiration is the complementary relationship method (Bouchet, 1963). The main advantage of this method is to require only standard meteorological variables. It does not need the surface specific parameters, like surface resistance, aerodynamic resistance, and soil moisture content. Several estimation models based on the complementary relationship have been proposed, which include the complementary relationship areal evapotranspiration (CRAE) model by Morton (1978) and the advection-aridity (AA) model by Brutsaert and Stricker (1979). A modified version of the advection-aridity (MAA) model was also proposed by Otsuki et al. (1984). Many studies have evaluated the validity of these models in different climate regions and with different time scales (e.g., Crago and Crowley, 2004; Hobbins et al., 2001a, b; Parlange and Katul, 1992; Xu and Singh, 2005). Hobbins et al. (2001a) reported that the estimation performance of the AA model increased when moving toward regions of increased climate control of evapotranspiration rates and decreased when moving toward regions of increased soil control. Xu and Singh (2005) also reported that several complementary relationshipbased models worked reasonably well for temperate humid regions, while the predictive accuracy fell when soil water content decreased. It is still needed to investigate the applicability of the complementary relationship-based models to the low soil moisture regions such as the urban area.

The primary objective of this study is to evaluate whether the above three complementary relationship models can apply to the urban area or not. For its purpose, the models are applied to six pairs of rural and urban areas of Japan which have very different meteorological variables. We compare the estimated values of evapotranspiration in the urban with those in the rural area, and demonstrate their characteristics. The main causes for the difference between the estimated evapotranspiration in rural area and that in urban area are examined by carrying out statistical tests. Furthermore, the relationship between urbanization and the actual evapotranspiration is discussed. Finally, we show the complementary relationship models applicable for the urban area.

\section{DESCRIPTION OF MODELS Complementary relationship}

The concept of a complementary relationship was first proposed by Bouchet (1963). He assumed a largely homogeneous surface of regional size. When the surface is saturated and evapotranspiration is only limited by the available energy, the potential evapotranspiration $\left(E_{p}\right)$ and the actual evapotranspiration $(E)$ equal the wet surface evapotranspiration $\left(E_{p o}, E=E_{p}=\right.$ $\left.E_{p o}\right)$. As the wet surface dries, while the available energy remains constant, $E$ decreases to a value below $E_{p o}$. As a result, a certain amount of energy $\left(q_{1}\right)$ occurs, that is,

$$
E=E_{p o}-q_{1}
$$


This energy $q_{1}$ primarily affects the air temperature, the air humidity, and the turbulence of the air near the surface. Bouchet (1963) supposed that this in turn causes an increase in $E_{p o}$ by $q_{1}$.

$$
E_{p}=E_{p o}+q_{1}
$$

Combining Eqs. (1) and (2) yields the following complementary relationship:

$$
E+E_{p}=2 E_{p o}
$$

We can calculate $E$ from $E_{p}$ and $E_{p o}$ by using Eq. (3).

There are several methods for estimating the actual evapotranspiration based on the complementary relationship. These methods, however, differ in their calculations of $E_{p}$ and $E_{p o}$. The three models used in this study, i.e., CRAE, AA, and MAA, are described below.

\section{CRAE model}

The CRAE model proposed by Morton (1978) is formulated as follows: First, the Penman's equation (1948) for potential evapotranspiration was modified as follows:

$$
E^{C R A E}=2 \varphi \frac{R_{n}^{\prime}+M}{l}-\left\{\frac{\Delta}{\Delta+\eta} \frac{R_{n}^{\prime}}{l}+\frac{\eta}{\Delta+\eta} \frac{F}{l}\left(e_{s}-e_{a}\right)\right\}
$$

where $E^{C A R E}$ is the actual evapotranspiration $\left(\mathrm{mm} \mathrm{d}^{-1}\right), \varphi$ is the energy-weighting factor $(-), R_{n}$ is the net radiation $\left(\mathrm{MJ} \mathrm{m}^{-2} \mathrm{~d}^{-1}\right)$, $\Delta$ is the slope of the saturation vapor pressure curve $\left(\mathrm{kPa} \mathrm{K}^{-1}\right), \eta$ is the heat transfer coefficient $\left(\mathrm{kPa} \mathrm{K}^{-1}\right), l$ is the latent heat of vaporization $\left(\mathrm{MJ} \mathrm{kg} \mathrm{kg}^{-1}\right), F$ is the vapor transfer coefficient $\left(\mathrm{MJ} \mathrm{m}^{-2} \mathrm{~d}^{-1} \mathrm{kPa}^{-1}\right)$, and $e_{a}$ and $e_{s}$ are the vapor pressure of the air and the saturation vapor pressure at air temperature, respectively $(\mathrm{kPa})$. The $\varphi$ is 1.26 which is the modified factor of the Priestley and Taylor equation (1972). The $\eta$ contains the effect of the long-wave radiation in addition to the psychrometric constant.

The complementary relationship needs the $E_{p}$ as shown in Eq. (3). Morton (1978) presented the following equation for the $E_{p}$ :

$$
E_{p}^{C R A E}=\frac{\Delta}{\Delta+\eta} \frac{R_{n}{ }^{\prime}}{l}+\frac{\eta}{\Delta+\eta} \frac{F}{l}\left(e_{s}-e_{a}\right)
$$

where $E_{p}^{C A R E}$ is the potential evapotranspiration modified by Morton (1978) $\left(\mathrm{mm} \mathrm{d}^{-1}\right)$.

The net radiation was estimated, using the following equation suggested by Morton (1978):

$$
R_{n}{ }^{\prime}=(1-\alpha) Q_{a}(0.18+0.55 n / N)-B
$$

where $\alpha$ is the albedo, $Q_{a}$ is the extra-atmospheric solar radiation, $n / N$ is the percentage of possible sunshine, and $B$ is the effective long wave radiation that will occur if the surface temperature equals the air temperature (Morton, 1978). The $\alpha$ is the value corresponding to land use types (Table 2). The $Q_{a}$ was calculated using the solar constant, latitude, and the day of year. The $B$ is estimated as follows:

$$
\begin{aligned}
& B=\varepsilon \sigma(t+273.2)^{4}\left\{1-\rho\left(0.707+e_{a} / 158\right)\right\} \\
& \rho=1+\left\{0.25-0.005\left(e_{s}-e_{a}\right)\right\}(C / 10)^{2}
\end{aligned}
$$

where $\varepsilon$ is the emissivity, $\sigma$ is the Stefan-Boltzmann constant, $t$ is the air temperature $\left({ }^{\circ} \mathrm{C}\right)$, and $C$ is the cloud amount.

Morton (1978) also modified the Priestley and Taylor equation (1972) to calculate the equilibrium evapotranspiration. The modified equation is written as:

$E_{p o}^{C R A E}=\varphi \frac{R_{n}+M}{\lambda}$

where $M$ is the advection energy $\left(\mathrm{MJ} \mathrm{m}^{-2} \mathrm{~d}^{-1}\right)$. The $M$ can be empirically calculated as:

$M=0.66 B-0.44 R_{n}^{\prime} \quad(M \geq 0)$

The substitution of Eqs. (5) and (9) into Eq. (3) yields the CRAE model, Eq. (4).

\section{AA model}

The AA model was suggested by Brutsaert and Stricker (1979). In this approach, $E_{p}$ is calculated by the Penman (1948) equation, as follows:

$E_{p}=\frac{\Delta}{\Delta+\gamma} \frac{R_{n}}{l}+\frac{\gamma}{\Delta+\gamma} E_{a}$

where $\gamma$ is the psychrometric constant $\left(=0.66 \mathrm{kPa} \mathrm{K}^{-1}\right), R_{n}$ is the net radiation, and $E_{a}$ is the drying power of the air. The $R_{n}$ was estimated using the following equation which had been used by Penman (1948):

$$
\begin{aligned}
& R_{n}=(1-\alpha) Q_{a}(0.18+0.55 n / N) \\
& -\sigma(t+273.2)^{4}\left(0.56-0.092 \times 0.866 \sqrt{e_{a}}\right)(0.1+0.9 n / N)
\end{aligned}
$$

The $\alpha$ in Eq. (12) is the value corresponding to land use types (Table 2) as same as in Eq. (6). The $E_{a}$ is generally described as:

$E_{a}=f\left(u_{z}\right)\left(e_{s}-e_{a}\right)$

where $u_{z}$ is the mean wind speed $\left(\mathrm{m} \mathrm{s}^{-1}\right)$ at a reference level $z(\mathrm{~m})$ above the ground and $f\left(u_{z}\right)$ is a function of $u_{z}\left(\mathrm{~m} \mathrm{kPa}^{-1} \mathrm{~d}^{-1}\right)$. In this study, estimations were conducted on a daily basis so that the effect of the atmospheric stability could be disregarded (Brutsaert, 2005). The following simple approach for $f\left(u_{2}\right)$, therefore, is available:

$$
f\left(u_{2}\right) \approx f\left(u_{2}\right)=2.6\left(1+0.54 u_{2}\right)
$$

The wet surface evapotranspiration for the AA model is calculated by the Priestley and Taylor (1972) equation as follows:

$$
E_{p o}^{A A}=\alpha \frac{\Delta}{\Delta+\gamma} \frac{R_{n}}{l}
$$

where $\alpha$ is a constant coefficient. The value of $\alpha$ was seen to vary slightly around 1.26 in most of the previous studies (e.g., Davies and Allen, 1973; Mukammal and Neumann, 1977; Stewart and Rouse, 1977; Thompson, 1975). The $\alpha=1.26$ is also used here. Further details on the AA model are shown in Brutsaert and Stricker (1979). The substitution of Eqs. (11) and (15) into Eq. (3) yields the AA model, namely, 


$$
E^{A A}=(2 \alpha-1) \frac{\Delta}{\Delta+\gamma} \frac{R_{n}}{l}-\frac{\gamma}{\Delta+\gamma} f\left(u_{2}\right)\left(e_{s}-e_{a}\right)
$$

where $E^{A A}$ is the actual evapotranspiration presented by Brutsaert and Stricker (1979) $\left(\mathrm{mm} \mathrm{d}^{-1}\right)$.

\section{MAA model}

This model was developed by Otsuki et al. (1984) to add the effect of advection to the AA model. Otsuki et al. (1984) noted that the AA model, compared with the water budget method, underestimates the actual regional evapotranspiration in winter, because the effect of advection is not considered in the model. Thus, advection term $M$, shown in Eq. (10) and derived from Morton's CRAE model, was added to the AA model. From this process, the MAA model is now expressed as

$$
E^{M A A}=(2 \alpha-1) \frac{\Delta}{\Delta+\gamma} \frac{R_{n}+M}{l}-\frac{\gamma}{\Delta+\gamma} f\left(u_{2}\right)\left(e_{s}-e_{a}\right)
$$

where $E^{M A A}$ is the actual evapotranspiration presented by Otsuki et al. (1984) $\left(\mathrm{mm} \mathrm{d}^{-1}\right)$.

\section{STUDY AREAS AND DATA}

The actual evapotranspiration was estimated in six rural areas of Japan: Iwamizawa in Hokkaido (IW), Shinjo in Yamagata (SH), Chichibu in Saitama (CB), Ueno in Mie (UE), Tsuyama in Okayama (TS), Izuka in Fukuoka (IZ) and in six urban areas near each of these rural areas: Sapporo in Hokkaido (SP), Sendai in Miyagi (SE), Otemachi in Tokyo (TK), Nagoya in Aichi (NA), Kuwata-cho in Okayama (OM), and Ohori in Fukuoka (FK) to compare the results from the two groups of areas. The location of each area is shown in Fig. 1. In these areas,

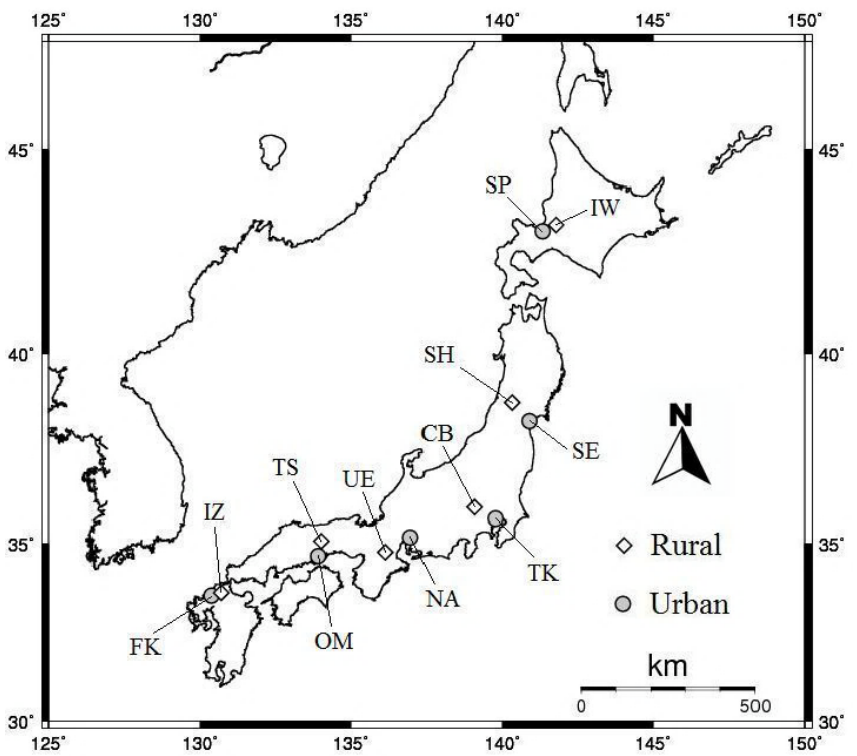

Fig. 1. Location of each study area. The squares represent the rural areas: Iwamizawa (IW), Shinjo (SH), Chichibu (CB), Ueno (UE), Tsuyama (TS), and Izuka (IZ), and the filled circles represent the urban areas: Sapporo (SP), Sendai (SE), Otemachi (TK), Nagoya (NA), Kuwata-cho (OM), and Ohori (FK). The meteorological variables in each area were measured by the Automated Meteorological Data Acquisition System (AMeDAS). the daily meteorological data used in this study, which were air temperature, relative humidity, wind speed, sunshine duration, and cloudiness, were measured by the Automated Meteorological Data Acquisition System (AMeDAS) managed by the Japan Meteorological Agency. For simplicity, we defined the study areas as being within a $5 \mathrm{~km}$ radius of the meteorological stations and assumed that the data represent the meteorological conditions in those areas. The data from January 1 to December 31, 2000 were used. Table 1 presents a summary of the meteorological conditions in each area.

Since evapotranspiration from the land surface is strongly influenced by the way in which the land is being used, information of the land use distribution around each meteorological station is required. We examined the distribution from an image analysis using the Geographic Information System (GIS) data presented by the Japan Ministry of Land, Infrastructure and Transport (JMLIT). Table 2 shows the areal fraction and the albedo for each land use in all the study sites. We assigned a surface albedo $\left(\alpha_{\mathrm{s}}\right)$ for each land use in the estimation of the net radiation. The values of the surface albedo used in this study were obtained from Kotoda (1986).

\section{RESULTS AND DISCUSSION Actual evapotranspiration}

The annual actual evapotranspiration estimated by the three models are shown in Fig. 2a (rural) and Fig. 2b (urban). The potential evapotranspiration calculated by the Penman (1948) equation is also shown because it is used as a reference for the three models. The actual evapotranspiration estimated in the urban areas was much less than that in the rural areas, especially between TK and CB. Fig. 3 shows the relationship between the complementary relationship-based actual evapotranspiration and the Penman potential evapotranspiration calculated in (a) rural and (b) urban areas. In the rural areas, the actual evapotranspiration values approximately corresponded to the potential ones. Those differences were relatively small. On the other hand, in the urban areas, the actual evapotranspiration values, especially estimated by the AA and the MAA models, were smaller than the potential ones. The differences among the models were larger in the urban areas than in the rural ones. This seems to reflect the lower surface moisture conditions, which in turn signifies that urban areas have a less evaporative environment.

Statistical tests were carried out to investigate the main causes of the difference in the estimated evapotranspiration between the rural and the urban areas. We used T-tests to identify which meteorological variables show a significant difference between the rural and the urban areas in annually averaged values. The T-test results are shown in Table 3. It is seen that the values for the air temperature and the vapor pressure deficit in urban areas were significantly larger than those in the rural areas by $1 \%$ significant level. There was not a significant difference between the two areas in regards to the other variables: the mean wind speed, the sunshine duration, and the cloudiness. Therefore, the higher values for the air temperature and the vapor pressure deficit cause the actual evapotranspiration estimated in the urban areas to be less than that in the rural areas.

Moriwaki and Kanda (2004) had measured the latent heat flux at Kugahara in Tokyo which is spatially close to TK, from May, 2001 to April, 2002, using an eddy correlation method. We converted the latent heat flux to the actual evapotranspiration. As a result, the evapotranspiration was $364.3 \mathrm{~mm} \mathrm{y}^{-1}$. This value is close to the actual evapotranspiration in TK estimated by the MAA model $\left(404.0 \mathrm{~mm} \mathrm{y}^{-1}\right)$. Though the estimation period 
Table 1. Summary of annual meteorological data for the period of 2000 in estimation areas. H: Altitude, P: Precipitation, T: Air temperature, VPD: Vapor pressure deficit, u2: Mean wind speed at 2-m above the ground, n: Sunshine duration, and c: Cloudiness. T, VPD, u2, n and $\mathrm{c}$ are annual mean values. $\mathrm{P}$ is annual total values. The minimum and maximum temperature are also shown in parentheses on $\mathrm{T}$ column.

\begin{tabular}{|c|c|c|c|c|c|c|c|c|}
\hline & $\begin{array}{c}\text { Site } \\
\text { location }\end{array}$ & $\begin{array}{c}\mathrm{H} \\
(\mathrm{m})\end{array}$ & $\begin{array}{c}\mathrm{P} \\
\left(\mathrm{mm}^{-1} \text { year }^{-1}\right)\end{array}$ & $\begin{array}{c}\mathrm{T} \\
\left({ }^{\circ} \mathrm{C}\right)\end{array}$ & $\begin{array}{l}\mathrm{VPD} \\
(\mathrm{hPa})\end{array}$ & $\begin{array}{c}\mathrm{u}_{2}^{*} \\
\left(\mathrm{~m} \mathrm{~s}^{-1}\right)\end{array}$ & $\begin{array}{c}\mathrm{n} \\
\left(\mathrm{h} \mathrm{d}^{-1}\right)\end{array}$ & $\begin{array}{l}\mathrm{c} \\
(-)^{* * *}\end{array}$ \\
\hline \multirow[t]{6}{*}{ Rural } & $\begin{array}{l}\text { Iwamizawa, Hokkaido, IW } \\
\left(43^{\circ} 13^{\prime} \mathrm{N}, 141^{\circ} 47^{\prime} \mathrm{E}\right)\end{array}$ & 42.3 & 1575.5 & $7.7(-20.7 \sim 33.9)$ & 1.8 & 2.3 & 4.2 & 7.8 \\
\hline & $\begin{array}{l}\text { Shinjo, Yamagata, SH } \\
\left(38^{\circ} 45^{\prime} \mathrm{N}, 140^{\circ} 19^{\prime} \mathrm{E}\right)\end{array}$ & 105.1 & 1932.5 & $11.1 \quad(-9.6 \sim 35.8)$ & 2.5 & 1.8 & 3.5 & $7.2^{* *}$ \\
\hline & $\begin{array}{l}\text { Chichibu, Saitama, CB } \\
\left(35^{\circ} 59^{\prime} \mathrm{N}, 139^{\circ} 04^{\prime} \mathrm{E}\right)\end{array}$ & 232.1 & 1128.0 & $13.5 \quad(-7.4 \sim 37.4)$ & 4.0 & 1.1 & 5.4 & $5.4^{* *}$ \\
\hline & $\begin{array}{l}\text { Ueno, Mie, UE } \\
\left(34^{\circ} 46^{\prime} \mathrm{N}, 136^{\circ} 09^{\prime} \mathrm{E}\right)\end{array}$ & 159.2 & 1307.5 & $14.6 \quad(-5.1 \sim 36.8)$ & 4.1 & 1.7 & 4.8 & $6.0^{* *}$ \\
\hline & $\begin{array}{l}\text { Tsuyama, Okayama, TS } \\
\left(35^{\circ} 04^{\prime} \mathrm{N}, 134^{\circ} 01^{\prime} \mathrm{E}\right)\end{array}$ & 145.7 & 1328.5 & $14.1 \quad(-5.2 \sim 36.3)$ & 3.7 & 1.1 & 5.1 & 7.0 \\
\hline & $\begin{array}{l}\text { Izuka, Fukuoka, IZ } \\
\left(33^{\circ} 39^{\prime} \mathrm{N}, 130^{\circ} 42^{\prime} \mathrm{E}\right)\end{array}$ & 37.1 & 1449.5 & $16.0 \quad(-3.2 \sim 35.4)$ & 4.9 & 1.7 & 5.5 & 6.5 \\
\hline \multirow[t]{6}{*}{ Urban } & $\begin{array}{l}\text { Sapporo, Hokkaido, SP } \\
\left(43^{\circ} 04^{\prime} \mathrm{N}, 141^{\circ} 20^{\prime} \mathrm{E}\right)\end{array}$ & 17.2 & 1444.5 & $9.0(-14.7 \sim 36.0)$ & 3.0 & 1.6 & 4.3 & 7.8 \\
\hline & $\begin{array}{l}\text { Sendai, Miyagi, SE } \\
\left(38^{\circ} 16^{\prime} \mathrm{N}, 140^{\circ} 54^{\prime} \mathrm{E}\right)\end{array}$ & 38.9 & 1186.5 & $12.9 \quad(-6.1 \sim 34.9)$ & 4.5 & 2.1 & 5.0 & 6.9 \\
\hline & $\begin{array}{l}\text { Otemachi, Tokyo, TK } \\
\left(35^{\circ} 41^{\prime} \mathrm{N}, 139^{\circ} 46^{\prime} \mathrm{E}\right)\end{array}$ & 6.1 & 1603.0 & $16.9(-0.7 \sim 37.8)$ & 7.8 & 2.1 & 5.4 & 6.4 \\
\hline & $\begin{array}{l}\text { Nagoya, Aichi, NA } \\
\left(35^{\circ} 10^{\prime} \mathrm{N}, 136^{\circ} 58^{\prime} \mathrm{E}\right)\end{array}$ & 51.1 & 1735.5 & $16.2 \quad(-3.9 \sim 37.9)$ & 6.2 & 2.2 & 5.9 & 6.3 \\
\hline & $\begin{array}{l}\text { Kuwatacho, Okayama, OM } \\
\left(34^{\circ} 40^{\prime} \mathrm{N}, 133^{\circ} 55^{\prime} \mathrm{E}\right)\end{array}$ & 2.8 & 813.0 & $16.5 \quad(-2.4 \sim 36.8)$ & 6.9 & 1.9 & 5.5 & 6.5 \\
\hline & $\begin{array}{l}\text { Ohori, Fukuoka, FK } \\
\left(33^{\circ} 35^{\prime} \mathrm{N}, 130^{\circ} 23^{\prime} \mathrm{E}\right)\end{array}$ & 2.5 & 1344.0 & $17.2 \quad(-0.2 \sim 35.9)$ & 6.7 & 1.8 & 5.5 & 6.3 \\
\hline
\end{tabular}

* Converted to 2-m height value by assuming logarithmic profile.

** Estimated from ratio of sunshine due to non-measurement of $\mathrm{c}$

*** (-) means that the unit of $\mathrm{c}$ is dimensionless.

Table 2. Areal fraction of each land use in estimation area. Forest in urban area was regarded as green space or garden trees. Industrial means playground, airport, racetrack, etc. "-" means there is no area of the land use. Building and pavement were regarded as urban elements. Albedo varies month by month.

\begin{tabular}{|c|c|c|c|c|c|c|c|c|c|c|}
\hline & \multirow[b]{2}{*}{ Site } & \multicolumn{9}{|c|}{ Areal fraction (\%) } \\
\hline & & Paddy field & Vegetation & Forest & Bare soil & Building & Pavement & Industrial & Water & Grass land \\
\hline \multirow[t]{6}{*}{ Rural } & $\begin{array}{l}\text { Iwamizawa, Hokkaido, } \\
\text { IW }\end{array}$ & 27.0 & 28.8 & 11.9 & 1.5 & 18.2 & 3.1 & 8.2 & 1.0 & - \\
\hline & Shinjo, Yamagata, SH & 36.6 & 7.4 & 38.0 & 0.6 & 10.8 & 0.6 & 3.5 & 1.1 & 1.4 \\
\hline & Chichibu, Saitama, CB & 3.8 & 11.3 & 55.3 & 3.3 & 13.2 & 1.8 & 4.5 & 4.9 & 1.9 \\
\hline & Ueno, Mie, UE & 32.1 & 3.4 & 39.1 & 1.3 & 11.3 & 2.3 & 4.5 & 5.9 & - \\
\hline & Tsuyama, Okayama, TS & 25.4 & 6.8 & 41.6 & 1.1 & 13.9 & 2.1 & 4.6 & 3.8 & 0.8 \\
\hline & Izuka, Fukuoka, IZ & 16.9 & 2.5 & 23.3 & 7.4 & 30.6 & 3.1 & 11.1 & 4.8 & - \\
\hline \multirow[t]{7}{*}{ Urban } & Sapporo, Hokkaido, SP & - & 1.1 & 18.7 & 2.1 & 59.2 & 7.1 & 9.5 & 2.0 & - \\
\hline & Sendai, Miyagi, SE & 3.1 & - & 6.1 & - & 70.2 & 6.0 & 11.9 & 2.0 & - \\
\hline & Otemachi, Tokyo, TK & - & - & 0.7 & - & 76.2 & 9.8 & 10.8 & 2.5 & - \\
\hline & Nagoya, Aichi, NA & - & - & 4.5 & - & 73.2 & 4.7 & 13.9 & 2.2 & 0.6 \\
\hline & $\begin{array}{l}\text { Kuwatacho, Okayama, } \\
\text { OM }\end{array}$ & 12.6 & 2.3 & 11.7 & 0.7 & 50.8 & 4.5 & 10.6 & 6.7 & - \\
\hline & Ohori, Fukuoka, FK & - & - & 1.8 & - & 77.4 & 3.8 & 13.8 & 2.6 & - \\
\hline & Albedo & $0.06-0.11$ & $0.16-0.18$ & $0.09-0.12$ & $0.26-0.32$ & $0.27-0.32$ & $0.27-0.32$ & $0.26-0.32$ & $0.06-0.11$ & $0.17-0.20$ \\
\hline
\end{tabular}



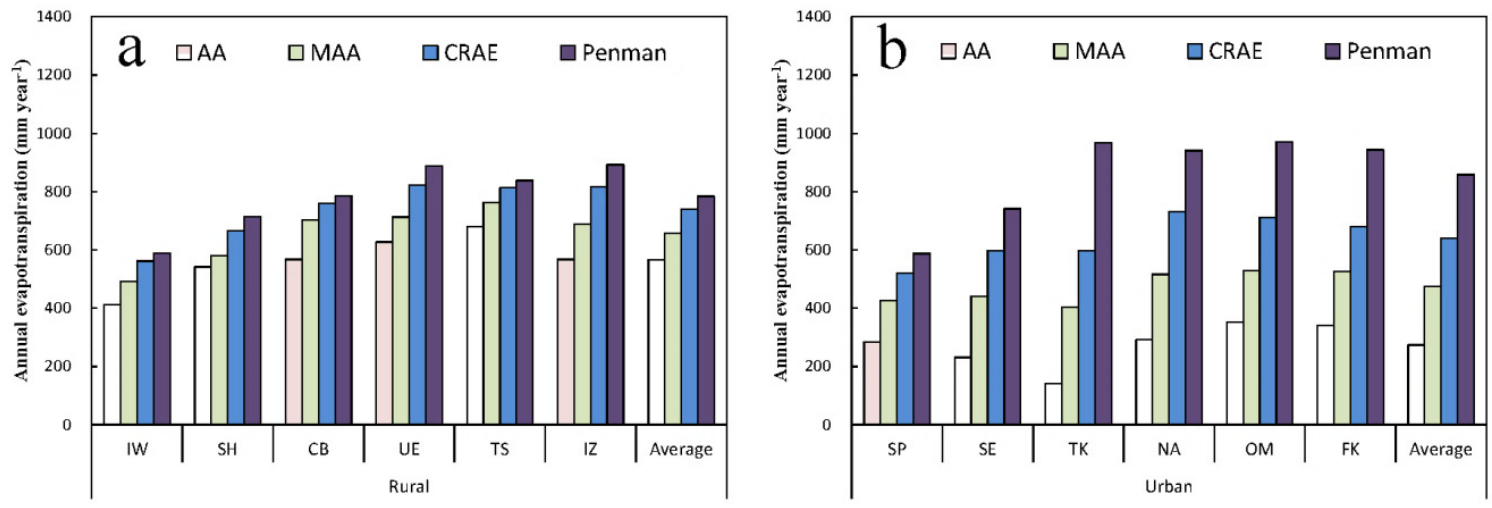

Fig. 2. Annual actual evapotranspiration estimated by the three complementary relationship-based models and potential evapotranspiration calculated with the Penman equation in (a) rural and (b) urban areas. The calculations were made on a daily basis for the year 2000.
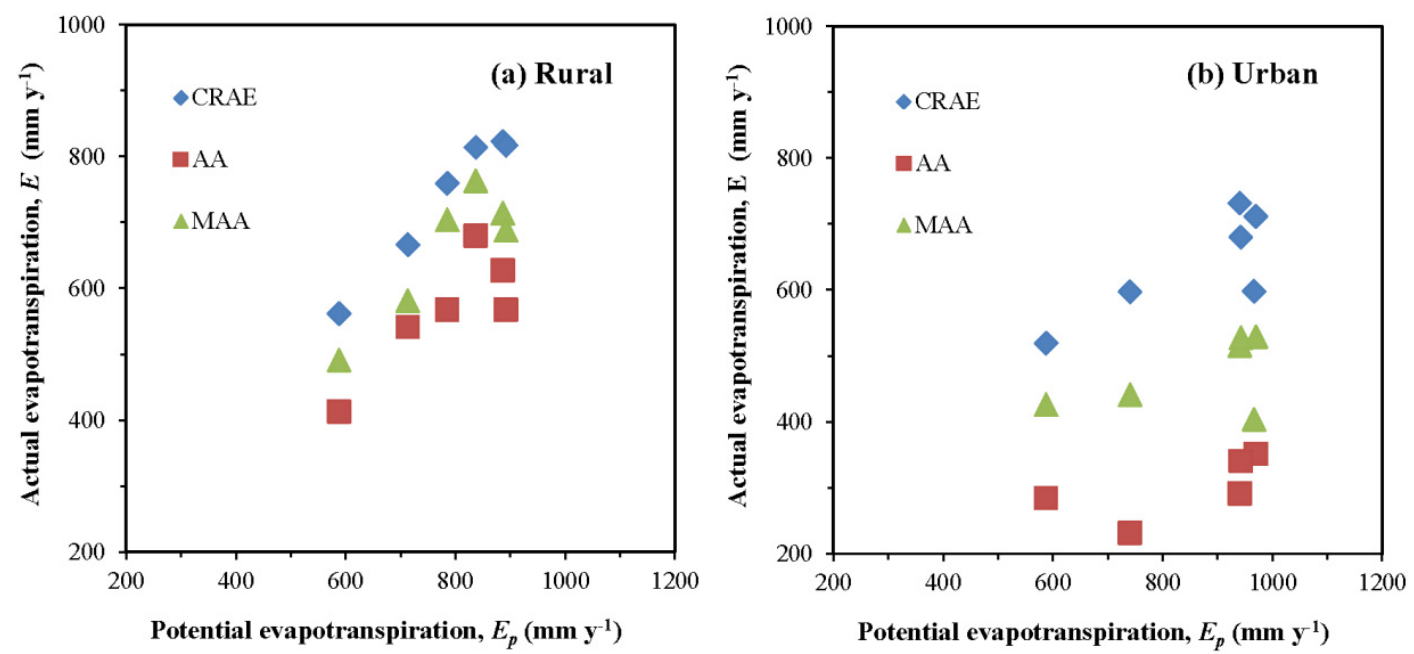

Fig. 3. The relationship between the complementary relationship-based actual evapotranspiration and the Penman potential evapotranspiration calculated in (a) rural and (b) urban areas. The calculations were made on a daily basis for the year 2000, as well as Fig. 2.

Table 3. The result of T-test performed to identify what meteorological variables have significant differences between rural and urban areas. Annually averaged values in urban and rural areas are displayed. T: Air temperature, VPD: Vapor pressure deficit, u2: Mean wind speed at 2-m above the ground, $\mathrm{n}$ : Sunshine duration, c: Cloudiness, and SD: significant difference.

\begin{tabular}{cccccc}
\hline & $\begin{array}{c}\mathrm{T} \\
\left({ }^{\circ} \mathrm{C}\right)\end{array}$ & $\begin{array}{c}\text { VPD } \\
(\mathrm{hPa})\end{array}$ & $\begin{array}{c}\mathrm{u}_{2}{ }^{*} \\
\left(\mathrm{~m} \mathrm{~s}^{-1}\right)\end{array}$ & $\begin{array}{c}\mathrm{n} \\
\left(\mathrm{h} \mathrm{d}^{-1}\right)\end{array}$ & $\mathrm{c}$ \\
\hline Rural & 12.8 & 3.5 & 1.6 & 4.8 & 7.0 \\
\hline Urban & 14.8 & 5.8 & 2.0 & 5.3 & 6.7 \\
\hline SD & $* *$ & $* *$ & &
\end{tabular}

* Converted to 2-m height value by assuming logarithmic profile.

** Variable has a significant difference between rural and urban areas at $1 \%$ significant level.

in the MAA model is different from that in the measurement, we consider that the annual actual evapotranspiration estimated by the MAA model in from 2000 to 2002 is approximately the same because the meteorological data for calculating the actual evapotranspiration were almost the same values. Watanabe et al. (2009) reported that the actual evapotranspiration estimated using the water balance method in Tokyo was $438 \mathrm{~mm} \mathrm{y}^{-1}$ on the annual means from 1971 to 2000 . From these previous studies, the MAA model can probably estimate the actual evapotranspiration in urban areas reasonably well. The difference in the actual evapotranspiration between the rural and the urban areas was at the maximum with the AA model (128 to 426 $\mathrm{mm} \mathrm{y}^{-1}$ ) and at the minimum with the CRAE model (42 to $161 \mathrm{~mm} \mathrm{y}^{-1}$ ). The difference with the MAA model varied from
65 to $299 \mathrm{~mm} \mathrm{y}^{-1}$, which was at an intermediate values between the CRAE model and the AA model. As shown in equation (17), in the MAA, the advection term, $M$, is added in the AA model of equation (16). The estimations of the MAA model were larger by the $M$ than those of the AA model. The CRAE model also includes the $M$. The differences between the CRAE and the MAA models was probably caused by some parameters in the CRAE which were different from those in AA and MAA, such as $R_{n}^{\prime}, F$, and $\eta$.

On the other hand, the potential evapotranspiration was greater in the urban areas. In general, the surface in urban areas is widely covered with asphalt and concrete, and any precipitation falling onto these surfaces immediately runs off. Therefore, the vapor pressure deficit in urban areas is very high (see Table 1), 
and this increases the potential evapotranspiration. Overall, the difference in the estimated values between the actual and the potential evapotranspiration were large in the urban areas (68 to $825 \mathrm{~mm} \mathrm{y}^{-1}$ ) and small in the rural areas $\left(24\right.$ to $\left.325 \mathrm{~mm} \mathrm{y}^{-1}\right)$. It was also shown that the difference in the evapotranspiration values estimated among the three models was larger in the urban areas. This indicates that each model has a different response to the meteorological variables, especially in the urban areas. The air temperature is needed to calculate all variables on the right hand side of equation (4), the $\Delta$, the $R_{n}$, the $l$, and the $e_{s}$ of equations (16) and (17), and the $M$ of equation (17). The vapor pressure deficit is equal to the term of $e_{s}-e_{a}$ in equations (4), (16), and (17). Since the values for the air temperature and the vapor pressure deficit are high in the urban areas and have the significant differences by $1 \%$ significant level, the sensitivity to these variables is different among the three models. The difference in values varied from 93 to $456 \mathrm{~mm} \mathrm{y}^{-1}$ in the urban areas and from 40 to $249 \mathrm{~mm} \mathrm{y}^{-1}$ in the rural areas.

\section{Actual evapotranspiration with each land use}

Fig. 4 shows the actual evapotranspiration estimated from each land use in TK and $\mathrm{CB}$. The results from the other sites are very similar to those shown in Fig. 4. Once again, the difference in the estimated evapotranspiration among the three models was larger in the urban areas (TK). The potential evapotranspiration in TK takes a very high value, especially from the water and the forest, which signifies green spaces or garden trees in the urban areas. The Penman (1948) equation can reasonably estimate the actual evapotranspiration from such humid surfaces, because the actual evapotranspiration equals the potential evapotranspiration when the surface has plenty of water. Moriwaki and Kanda (2003) indicated that vegetation in urban areas has a potential to release the latent hear flux equaling or exceeding in magnitude the net radiation received, due to the oasis effect. If the latent heat fluxes from water and green spaces are as much as the net radiation, the annual evapotranspiration from water and green spaces in TK will reach about 1110 and $1030 \mathrm{~mm} \mathrm{y}^{-1}$, respectively. These values are compatible with the potential evapotranspiration shown in Fig. 3. Therefore, the three models based on the complementary relationship obviously underestimated the actual evapotranspiration from such surfaces. Although the areas of water and green spaces are few, the magnitude of the underestimation is so large that the error derived from this underestimation is significant.

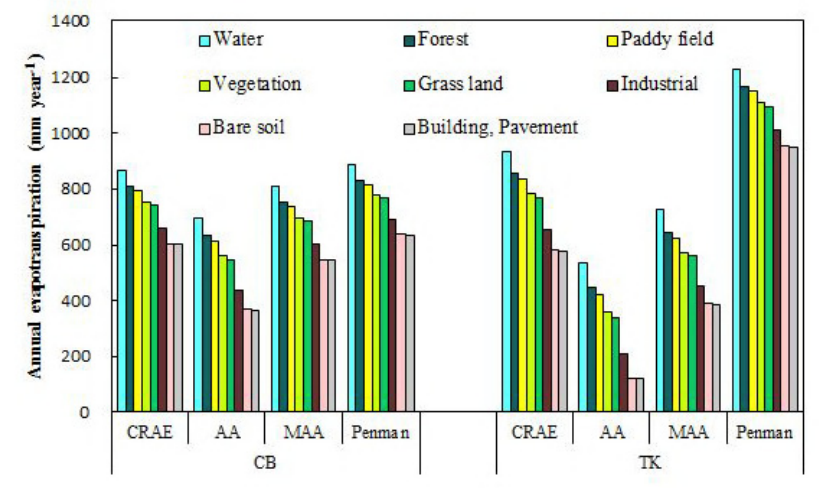

Fig. 4. Annual actual evapotranspiration from each land use at $\mathrm{CB}$ (Chichibu in Saitama) and TK (Otemachi in Tokyo). The difference in evapotranspiration between land uses was derived from the difference in albedo without considering those in temperature and vapor pressure deficit. Similar results were obtained from other areas.

\section{Relation between urbanization and the ratio of $E$ to $E_{p}$}

If urbanization advances and the ratio of the impervious surface increases, the mean surface moisture probably decreases. According to Brutsaert (2005) and Kahler and Brutsaert (2006), the ratio of actual evapotranspiration $E$ to potential evapotranspiration $E_{p}$ can be regarded as the surface moisture index. Therefore, the relation between urbanization and the ratio of $E$ to $E_{p}$ was investigated. The areal fractions for the buildings and the impervious surfaces in each area and the corresponding ratio of $E$ to $E_{p}$ are shown in Fig. 5. In all the models, the ratio of $E$ to $E_{p}$ has a high correlation with urbanization. The ratio is seen to decrease with the progress of urbanization, while the actual evapotranspiration approached the potential evapotranspiration in rural areas. This means that the three complementary relationship-based models can take into account the effect of urbanization. Since the linear regression coefficients are different among these three models, the models have different responses to urbanization. The slope of the regression line is the smallest for the AA model and the largest for the CRAE model. The MAA model has a slope intermediate between the AA model and the CRAE model. The ratio of $E$ to $E_{p}$ at Kugahara (Moriwaki and Kanda, 2004) is also shown in Fig. 4. The ratio at Kugahara is really close to the ratio of the MAA model at TK. This also indicates that the MAA model can probably estimate the actual evapotranspiration in urban areas reasonably well.

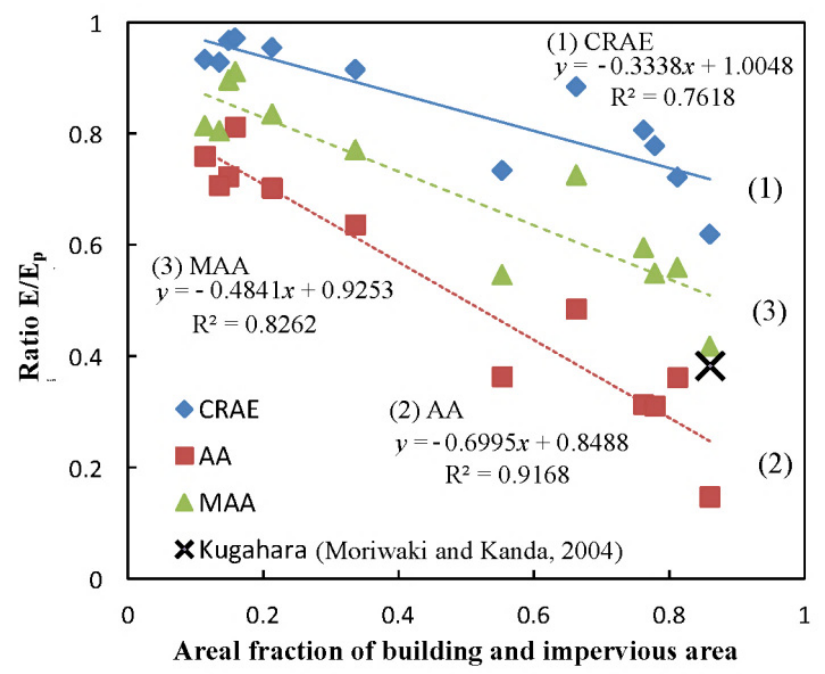

Fig. 5. Ratio $E / E_{p}$ versus areal fractions for buildings and impervious areas. The areal fractions for the buildings and the impervious areas were regarded as indices of urbanization.

\section{CONCLUSIONS}

To evaluate the applicability of the complementary relationship-based models to the urban area where soil moisture is generally low, the characteristics of evapotranspiration estimated by three complementary relationship-based models (i.e., CRAE, AA, and MAA) were investigated in six pairs of rural and urban areas of Japan. The main results obtained in the present study were as follows:

1) The MAA model could estimate the actual evapotranspiration most reasonably among the three models.

2) The actual evapotranspiration estimated in the urban areas was much less than that in the rural areas. The T-tests showed that the higher values for air temperature and the va- 
por pressure deficit in the urban areas caused a significant difference between rural and urban areas.

3) The difference in estimated values of evapotranspiration in the urban areas was significant, depending on each model, while the difference in values in the rural areas was relatively small. This was mainly because each model had a different sensitivity to the air temperature and the vapor pressure deficit.

4) Compared with the estimation results of the Penman equation, it was shown that all three models underestimate the actual evapotranspiration in the urban areas from humid surfaces, like water and green spaces.

5) The clear relationship between the ratio of an impervious area and the ratio of $E$ to $E_{p}$ showed that each model took into account the effect of urbanization. In addition, the linear regression coefficients are different among the three models so that the models have different responses to urbanization.

We could not validate this new finding by comparing the estimation results with the observations, because the actual evapotranspiration in the urban areas had scarcely been observed. For a more precise evaluation of the results in this study, the estimations and the measurements of evapotranspiration in the same urban areas will be needed.

Acknowledgement. The authors are grateful for the Kanda Laboratory of the Tokyo Institute of Technology for making available the data of Kugahara. The GIS data for land use distribution were provided by the Japan Ministry of Land, Infrastructure and Transport (MLIT).

\section{REFERENCES}

Bouchet, R.J., 1963. Evapotranspiration reelle et potentielle, signification climatique. [Actual and potential evapotranspiration, climatic significance]. General Assembly Berkeley Int. Assoc. Sci. Hydrol. Gentbrugge. Belgium. Publ., No. 62, 134-142. (In French.)

Brutsaert, W., 2005. Hydrology: An Introduction. University Press, Cambridge, Dordrecht.

Brutsaert, W., Stricker, H., 1979. An advection-aridity approach to estimate actual regional evapotranspiration. Water Resources Research, 15, 2, 443-450.

Crago, R., Crowley, R., 2004. Complementary relationships for near-instantaneous evaporation. Journal of Hydrology, 300, 199-211.

Davies, J.A., Allen, C.D., 1973. Equilibrium, potential, and actual evaporation from cropped surfaces in southern Ontario. Journal of Applied Meteorology, 12, 649-657.

Hobbins, M.T., Ramirez, J.A., Brown, T.C., 2001a. The complementary relationship in estimation of regional evapotranspiration: an enhanced advection-aridity model. Water Resources Research, 37, 1389-1403.

Hobbins, M.T., Ramirez, J.A., Brown, T.C., Claessens, L., 2001b. The complementary relationship in estimation of regional evapotranspiration: the complementary relationship areal evapotranspiration and advection-aridity models. Water Resources Research, 37, 1367-1387.
Kahler, D.M., Brutsaert, W., 2006. Complementary relationship between daily evaporation in the environment and pan evaporation. Water Resources Research, 42, W05413. doi:10.1029/2005WR004541.

Kotoda, K., 1986. Estimation of river basin evapotranspiration. Environmental Research Center Papers. University of Tsukuba, 8, 1-92.

Monteith, J.L., 1965. Evaporation and environment. Symp. Soc. Exp. Biol., 19, 205-234.

Moriwaki, R., Kanda, M., 2003. Radiation, heat, water vapor and $\mathrm{CO}_{2}$ fluxes in an urban surface layer. Journal of Japan Society of Hydrology and Water Resource, 16, 5, 477-490 (In Japanese with English abstract.)

Moriwaki, R., Kanda, M., 2004. Seasonal and diurnal fluxes of radiation, heat, water vapor, and carbon dioxide over a suburban area. Journal of Applied Meteorology, 43, 1700-1710.

Morton, F.I., 1978. Estimating evapotranspiration from potential evaporation: practicality of an iconoclastic approach. Journal of Hydrology, 38, 1-32.

Mukammal E.I., Neumann H.H., 1977. Application of the Priestley-Taylor evaporation model to assess the influence of soil moisture on the evaporation from a large weighing lysimeter and class A pan. Boundary Layer Meteorology, 14, 243-256.

Otsuki, K., Mitsuno, T., Maruyama, T., 1984. Comparison between water budget and complementary relationship estimates of catchment evapotranspiration. Transactions of The Japanese Society of Irrigation, Drainage and Rural Engineering, 112, 17-23 (In Japanese with English abstract.)

Parlange, M.B., Katul, G.G., 1992. An advection-aridity evaporation model. Water Resources Research, 28, 127-132.

Penman, H.L., 1948. Natural evaporation from open water, bare soil and grass. Proceedings of Royal Society London A, 193, 120-146.

Priestley, C.H., Taylor, R.J., 1972. On the assessment of surface heat flux and evaporation using large-scale parameters, Monthly Weather Review, 100, 81-92.

Stewart, RB, Rouse, WR., 1977. Substantiation of the Priestley and Taylor parameter $\alpha=1.26$ for potential evaporation in high latitudes. Journal of Applied Meteorology, 6, 649-650.

Thompson, J.R., 1975. Energy budgets for three small plotssubstantiation of Priestley and Taylor's large-scale evaporation parameter. Journal of Applied Meteorology, 14, 13991401 .

Watanabe, H., Murakami, M., Komura T., Moroizumi, T., Furumai, H., 2009. Evaluation of water balance and water use stress in principal cities in Japan. Journal of Water and Wastes, 51, 2, 137-148. (In Japanese.)

Xu, C.-Y., Singh, V.P., 2005. Evaluation of three complementary relationship evapotranspiration models by water balance approach to estimate actual regional evapotranspiration in different climatic regions. Journal of Hydrology, 308, 105-121.

Received 27 December 2013 Accepted 21 October 2014

Note: Colour version of Figures can be found in the web version of this article. 